\title{
The Application of Practical Project-Based Approach in Police English Teaching
}

\author{
Jun Liang*
}

China People's Police University, Lang Fang, China

*Corresponding author

\begin{abstract}
The practical project-based approach integrates teaching with training and practicing, which is a teaching activity enrolled with "learning project" by teacher and students. The practical project-based approach improves the learning and knowledge construction with the help of training and practicing to gain the skills of understanding the knowledge and solving the problems. The Practical project-based approach can improve the problem of the separation of theoretical learning and training. It accords with the connotation development of higher education and is suitable for the needs of China's modern police talents. It also meets the requirements of the developments of teaching methods and reform of courses in China's police universities, which is worth our research, practice and promotion.
\end{abstract}

Keywords: Police English, Project-based approach, Training and practicing

\section{实训实践型项目教学法在警务英语教学中的应用}

\author{
梁军*
}

中国人民警察大学，廊坊，中国

“通讯作者

\section{中文摘要}

实训实践型项目教学是一种融课堂教学和实训实践于一体的教学模式, 是教师和学生在共同实施一个 完整的 “习得项目” 过程中从事的教学活动。它把学生的学融入到有意义的完成任务的过程中, 让学 生自主地学习和进行知识建构, 积极地参与实训实践活动, 从而获得理解知识和解决问题的能力。实 训实践型项目教学法能有效改善理论学习与实训实践相分离的弊端, 符合高等教育的人才培养目标和 我国现代化公安人才的需要, 以及我国公安院校教学与课程改革的发展的诉求, 值得我们进行深入的 探索研究、实践推广。

关键词: 警务英语; 项目教学法; 实训实践

\section{1. 概念与背景}

实训实践型项目教学法是一种以项目任务为驱动 的教与学的实践教学模式。它是以教师为主导、学生为 主体、项目为载体、任务为驱动、以职业能力培养为目 标, 以社会需求为背景的系统的教学方法。它融合了探 究教学法、任务驱动教学法和案例教学法的特点, 是以 行动为导向的学习过程。其中它的核心概念项目一词指 的是 “通过多个活动综合培养各项技能的延展性任务。 这些活动组合之后形成共同的教学目标, 可能包括的步 骤: 制定计划, 通过读、听、访谈、实训实践等手段收
集信息，讨论信息，解决问题，口头或书面汇报，成果 展示”。

国内应用项目教学法的实践很多, 但应用于外语课 堂的实例却是少数。其中大多是用于高职高专外语课程 的英语教学, 而用于警务英语教学的研究却非常少。随 着近年来我国改革开放工作的不断深入, 在涉外警务或 者国际警务的交流、合作方面的表现也更加频繁, 与此 同时，国内的涉外案件不断呈现高发态势。其中，证件 识别、外国人的居住管理、涉外接待、接警、报警和 “三 非”案件对基层民警的外语能力要求较多, 需要基层的 执法者能够具备基本的警务英语知识, 从容应对国内各 项涉外事件。另一方面, 国际维和警察、国际刑警组织 
和国际警察会议的国际业务合作也需要警察具备较强 的二语语言能力, 能够做到和国外执法者开展交流, 体 现我国执法者在国际警务事务中的重要作用。但是就警 务英语教学开展的实际情况来看, 仍然与现代化的公安 人才需求存在较大的差距, 警务英语教学体系存在不完 善之处。同时, 通过对福建警察学院、浙江警察学院、 山东警察学院和辽宁警察学院的走访以及与本校 (中国 人民警察大学) 教师的交流, 多数教师反映他们的警务 英语教学模式仍以传统的 PPP (present, practice, product) 教学模式为主, 另外警务英语教学模式陈旧、 单一仍然为英语教学体系中薄弱的一环。由此可见, 警 务英语教学模式亟待改革。

\section{2. 研究方法}

实训实践型项目教学法以建构主义理论和合作学 习理论为理论基础。建构主义理论的核心在于 “从做中 学”、“实践出真知”, 因此, 如何实践以及采取何种 实践形式和内容就成为实施建构主义教学理念的重要 内容。著名的心理学家皮亚杰提出的建构主义学习理论 认为, 知识不是通过教师传授得到的, 而是学生在一 定的情景下, 借助他人 (包括教师和同学) 的帮助, 利 用必要的学习资料, 通过意义建构的方式而获得。本文 以建构主义学习理论为基础, 采用调查问卷、项目成果 交流, 教师和实训实践单位评价的研究方法, 以定性研 究为主, 辅以定量研究, 从而分析实训实践型警务英语 项目教学模式的可行性。

\section{3. 行动方案的制订与实施}

在选定教学方法之后, 接下来的步骤就是制定项目 方案、实施方案和展示及评估项目成果三个阶段。

\section{1. 制订项目方案阶段}

这一阶段包括选定试验班级和划分学习小组、讨论
以《警务英语》教材为基础结合学生在公安机关的实训 实践活动设计和确定项目任务。首先, 教师向学生详细 介绍项目依托式学习的概念、特点及实施过程，重点强 调项目成果评价主要采用形成性评价, 包括同伴自评、 小组互评和教师综合评分，使他们对新的教学方法有理 性的认识, 对师生角色的转变做好心理准备。然后, 组 织学生依据自愿加入、优势互补的原则划分学习小组, 每组 4-6 人, 选定小组长。接着, 教师以《警务英语》 教材为基础, 结合在公安机关实训实践工作内容, 将项 目任务划分为国际警务合作、反恐、缉毒、网络犯罪、 出入境管理、公共安全管理、安全检查、询问八个大项 目 (每个项目计划教学时数为 4 学时)。

\section{2. 项目实施阶段}

首先, 教师在课堂上针对教材, 进行主题式的警务 英语阅读、口语和应用文写作基础知识的串讲; 然后, 教师经过与项目组成员的课堂讨论, 开始指导学习小组 制定项目计划书; 接下来，教师通过所在单位与当地公 安机关积极联系, 分派项目组成员到公安机关相关部门 进行实训实践活动, 并就各自承担的子项目搜集相关资 料, 加以分析、归纳、总结。然后, 确定展示方式 (如 PPT 辅助报告、情节剧、辩论大赛、调查报告等), 并完 成项目成果制作和演练等。

\section{3. 项目成果展示及评估阶段}

这一阶段主要由项目成果交流, 教师和公安机关相 关部门评价组成。项目小组成员、其他小组成员及教师 要针对项目主题的选取、计划的制订、活动探究阶段的 表现、成果展示及交流的完成情况进行评价。同时，公 安机关相关部门也会根据项目小组成员在完成任务过 程中所展现的合作能力、协调能力、解决问题的能力进 行综合评价。评价项目成果（见表 1 和表 2)。

表 1 项目成果评价表

\begin{tabular}{|c|c|c|c|c|c|}
\hline 步骤 & 评价内容 & 自 评 $(20 \%)$ & 互评 (20\%) & 师评 (30\%) & 实践单位测评 (30\%) \\
\hline 准备 & 前期准备 (20 分) & & & & \\
\hline \multirow{5}{*}{$\begin{array}{c}\text { 项目进行 } \\
\text { 过程 }\end{array}$} & 参与度（10 分） & & & & \\
\hline & 合作精神 (10 分) & & & & \\
\hline & 创新精神 (10 分) & & & & \\
\hline & 解决能力 (10 分) & & & & \\
\hline & 应用能力 (10 分) & & & & \\
\hline 展示 & 成果质量 (30 分) & & & & \\
\hline 总分 & 100 分 & & & & \\
\hline
\end{tabular}


表 2 项目成果评价表

\begin{tabular}{|l|l|l|l|l|l|l|}
\hline \multirow{2}{*}{ 评价内容 } & \multirow{2}{*}{ 分值 } & \multicolumn{2}{|l|}{ 评价主体 } & \multirow{2}{*}{ 综合评分 } \\
\cline { 3 - 6 } & & 自评 & 互评 & 师评 & 实践单位测评 & \\
\hline 任务设计符合项目要求 & 20 & & & & & \\
\hline 设计贴切、内容丰富 & 20 & & & & & \\
\hline 语言准确、表达流利、应用能力强 & 30 & & & & & \\
\hline 互动、合作 & 20 & & & & & \\
\hline 熟练运用多媒体 & 10 & & & & & \\
\hline 总分 & 100 & & & & & \\
\hline
\end{tabular}

\section{4. 实验结果讨论}

通过统计分析, 对比实训实践型项目教学开展前后 学生警务英语学习态度、学习效率以及与公安专业结合 能力水平的变化, 项目教学法取得了良好的效果, 主要 体现在学生学习动机提高、语言能力进步、学习者自主 性增强以及解决实际问题能力的提升。

\section{1. 对测试数据的分析}

（1）试验班与参照班知识水平前测成绩对比分析 以 2019 年上学期, 警务英语课程的期末考试作为 实验前测, 通过对比两个班级学生的警务英语基础知识 水平的统计分析, 如图表所示, 发现试验班与参照班的 警务英语成绩无显著差异。如表 3 所示:

表 3 试验班与参照班英语基础知识前测对比表

\begin{tabular}{|l|l|l|l|l|l|}
\hline 班级 & 人数 & $\begin{array}{l}\text { 平 均 } \\
\text { 分 }\end{array}$ & $\begin{array}{l}\text { 及 格 } \\
\text { 率 }\end{array}$ & $\begin{array}{l}\text { 最高 } \\
\text { 分 }\end{array}$ & $\begin{array}{l}\text { 最低 } \\
\text { 分 }\end{array}$ \\
\hline $\begin{array}{l}\text { 试 验 } \\
\text { 班 }\end{array}$ & 40 & 69.8 & $80 \%$ & 91 & 51 \\
\hline $\begin{array}{l}\text { 参照 } \\
\text { 班 }\end{array}$ & 41 & 72 & $80.6 \%$ & 89.5 & 54 \\
\hline
\end{tabular}

（2）试验班与参照班知识水平后测成绩对比分析

经过一学期教学实验后, 试验班和参照班的警务英 语期末卷面成绩，产生了显著性差异，如图表所示对前 测后测的分析数据表明: 项目教学法可以提高学生的学 习成绩，教学效果明显。如表 4 所示:

表 4 试验班与参照班英语基础知识后测对比表

\begin{tabular}{|l|l|l|l|l|l|}
\hline 班级 & 人数 & $\begin{array}{l}\text { 平均 } \\
\text { 分 }\end{array}$ & $\begin{array}{l}\text { 及 格 } \\
\text { 率 }\end{array}$ & $\begin{array}{l}\text { 最 高 } \\
\text { 分 }\end{array}$ & $\begin{array}{l}\text { 最 低 } \\
\text { 分 }\end{array}$ \\
\hline 试验班 & 40 & 80.4 & $91.6 \%$ & 95 & 51 \\
\hline 参照班 & 41 & 73.6 & $85.7 \%$ & 88 & 52 \\
\hline
\end{tabular}

\section{2. 对调查问卷数据的分析}

在临近学期结束, 通过问卷调查的方式, 收集试验 班学生对教学的反馈, 问卷调查共发放了 40 份, 收集 了 38 份占问卷数的 $95 \%$, 笔者将问卷调查进行综合, 并 统计如下: 


\begin{tabular}{|c|c|c|c|c|c|c|c|}
\hline \multicolumn{8}{|c|}{ 表 5 调查问卷数据表 } \\
\hline 序号 & 调查内容 & 选项 & 人数 & 选项 & 人数 & 选项 & 人数 \\
\hline 1 & $\begin{array}{l}\text { 能否有效学习警 } \\
\text { 务英语 }\end{array}$ & 非常有效 & 34 & 有效 & 2 & 一般 & 2 \\
\hline 2 & $\begin{array}{l}\text { 是否喜欢项目教 } \\
\text { 学法 }\end{array}$ & 非常喜欢 & 32 & 喜欢 & 5 & 一般 & 1 \\
\hline 3 & $\begin{array}{l}\text { 项目教学法提高 } \\
\text { 了哪些能力 } \\
\text { (多选) }\end{array}$ & $\begin{array}{l}\text { 信息搜集能 } \\
\text { 力 }\end{array}$ & 33 & 语言运用能力 & 35 & 团队协作能力 & 37 \\
\hline 4 & $\begin{array}{l}\text { 是否提高了警务 } \\
\text { 英语能力 }\end{array}$ & 很明显 & 33 & $\begin{array}{l}\text { 明显 } \\
\end{array}$ & 2 & 一般 & 3 \\
\hline 5 & $\begin{array}{l}\text { 团队合作中, 你 } \\
\text { 倾向于 }\end{array}$ & $\begin{array}{l}\text { 组织并安排 } \\
\text { 项目活动 }\end{array}$ & 11 & $\begin{array}{l}\text { 积极参与独立 } \\
\text { 完成 }\end{array}$ & 5 & $\begin{array}{l}\text { 其他组员合作 } \\
\text { 完成 }\end{array}$ & 22 \\
\hline 6 & $\begin{array}{l}\text { 你在团队协作中 } \\
\text { 的收获（多选） }\end{array}$ & 分工与合作 & 35 & $\begin{array}{l}\text { 分享资源协力 } \\
\text { 解决 }\end{array}$ & 31 & $\begin{array}{l}\text { 分析解决问题 } \\
\text { 的能力 }\end{array}$ & 34 \\
\hline 7 & $\begin{array}{l}\text { 希望教师扮演的 } \\
\text { 角色 }\end{array}$ & $\begin{array}{l}\text { 传授课本知 } \\
\text { 识 }\end{array}$ & 1 & 教授应试技巧 & 2 & $\begin{array}{l}\text { 项目教学与英 } \\
\text { 语 }\end{array}$ & 35 \\
\hline
\end{tabular}

通过上述数据得出结论: 大多数学生认为能有效提 高警务英语并且非常认同项目化教学方法; 在小组合作 中, 学生更倾向于与其他组员完成任务, 因此在任务设 计上, 应多安排互动协作; 在整个教学过程中, 学生更 愿意老师在项目教学中扮演的角色是项目指导与应用 而非传统的知识传授。

实训实践型项目教学不仅使学生的语言学习受益, 其他方面的能力也得到了提高。因为项目教学本身就 是实践型教学, 所以一个直接的影响就是初步培养了学 生解决实际问题的能力, 他们在问卷中反映出通过参与 项目, 自己提高了分析并解决问题的能力, 学到了更多 同以后工作相关联的知识, 促进了合作精神, 还收获了 与同学间更深厚的友谊。

\section{5. 几点建议}

\section{1. 建立警务英语教学项目库}

建立能够通过项目导引警务英语教学的项目库非 常重要。项目库中的项目应以相关联模块的警务英语知 识来构建操作性强的子项目, 如警务英语教学设计 (子 项目: 教材分析、教案编写等)、警务英语教学知识 (子 项目: 英语阅读教学, 语法、词汇教学等)、语言运用 技能训练 (子项目: 涉外警情处理等) 等等。其中, 重
点以警务英语运用技能的训练为主, 知识点的学习为辅。 同时, 要明确每个项目中的各项教学任务的性质要求。 最后, 要根据学生的实际水平控制好项目的难易度

\section{2. 关注对项目教学评价的过程与多元化}

实训实践型项目教学法强调对学生综合运用知识 与技能解决实际问题的过程与能力的评价, 因此要凸显 对过程的评价与方法的多元化。评价的过程性主要是指 教师要关注教研小组项目开展的过程和学生在学习和 实训实践中的进步程度, 考察学生的参与度和合作情况。 评价多元化体现在组内自评、小组互评、教师评价与实 训实践单位评价相结合; 终结性评价与形成性评价结合, 但要注重过程性评价。

\section{6. 小结}

实训实践型项目教学是一种新兴发展的教学方法, 在教育领域中应用颇多, 但目前在警务英语课程方面的 实验研究还零塞无几。将具有实践性和应用性特点的项 目实训实践项目教学法应用于警务英语教学中, 从教学 取向上应用型目的的逐步重视、到教学内容上的灵活与 丰富、项目实训实践教学活动与情境的创设以及结果评 价的多元化, 有效解决了现有警务英语课堂教学中存在 
的弊端, 改善了警务英语课堂的教学效果, 学生的警务 英语应用能力与综合能力得到了提升, 是一次有意义的 尝试。

\section{致谢}

本文为中国人民警察大学中青年教师科研创新计 划《“一带一路” 背景下警务英语项目教学模式研究》 的阶段性成果之一。

\section{REFERENCES}

[1] Blumenfeld, P., Soloway, E., Marx, R., Krajcik, J., Guzdial, M., \& Palincsar, A. "Motivating Project-Based Learning: Sustaining the doing, supporting the learning" [J]. Educational Psychologist. 1991. 26(3-4), 369-398.

[2] Brown, H. D. Teaching by principles: An interactive approach to language pedagogy [M]. Englewood Cliffs, NJ: Prentice Hall Regents. 1994.

[3] Deci, E. L. \& Ryan, R. M. Handbook of Self-determination $[\mathrm{M}]$. Rochester, NY: University of Rochester Press. 2002.

[4] Markham T, Larmer J \& Ravitz J. Project Based Learning Handbook: A Guide to Standards-focused Project Based Learning (2nd Ed.) [M]. Novato, California: Buck Institute for Education, 2003.

[5] Moss, D. \& Van Duzer, C. Project-based Learning for Adult Language Learners [J]. ERIC/NCLE Digest. 1998.

[6] Noels, K. A. Pelletier, L. G, \& Vallerand, R. J. Why are You Learning a Second Language? Motivational Orientations and Self-determination Theory [J]. Language Learning, 2000. 50: 57-85. 